Article

\title{
Healthcare Reform Repeal Efforts in the United States in 2017: An Inquiry into Public Advocacy Efforts by Key Interest Groups
}

\author{
John Hoornbeek ${ }^{1, *}$, Bethany Lanese ${ }^{2}$, Mutlaq Albugmi ${ }^{1}$ and Joshua Filla ${ }^{1}$ \\ ${ }^{1}$ Center for Public Policy and Health, College of Public Health, Kent State University, Kent, OH 44242, USA; \\ E-Mails: jhoornbe@kent.edu (J.H.), malbugmi@kent.edu (M.A.), jfilla@kent.edu (J.F.) \\ 2 College of Public Health, Kent State University, Kent, OH 44242, USA; E-Mail: blanese1@kent.edu \\ * Corresponding author
}

Submitted: 30 March 2018 | Accepted: 28 September 2018 | Published: 19 October 2018

\begin{abstract}
The Affordable Care Act (ACA) was subjected to repeated repeal and replace efforts in the United States Congress in 2017. Attempts to repeal and replace the law failed, but penalties for not complying with its mandate that individuals purchase health insurance were removed in tax legislation passed late in the year and administrative actions taken by President Trump yielded additional concerns about the stability of the law's reform approach and the expanded health insurance access that it created. This article explores public advocacy efforts by key interest groups from three major policy sectorshealth providers, the insurance industry, and the business community-that had served as an "axis of opposition" to past American healthcare reform efforts. It identifies resource and incentive policy feedback effects that appear likely to influence these groups due to design features of the ACA and assesses whether patterns of advocacy efforts in 2017 are consistent with what might be expected if these design features had their predicted effects. Our assessment reveals patterns of interest group advocacy that are consistent with what might be expected to arise from resource and incentive based policy feedback effects, and interest group political dynamics that differ from what was in place prior to passage of the ACA. It also reveals advocacy patterns that are not well explained by resource and incentive based policy feedback effects, and-in so doing-yields insights that are relevant to the design of policy reforms and future research.
\end{abstract}

\section{Keywords}

Affordable Care Act; Obamacare; policy feedback; policy design; policy reform; resource-incentives; resource effects; sustainability of policy reforms

\section{Issue}

This article is part of the 'Multidisciplinary Studies' issue in Politics and Governance.

(C) 2018 by the authors; licensee Cogitatio (Lisbon, Portugal). This article is licensed under a Creative Commons Attribution 4.0 International License (CC BY).

\section{Introduction}

During 2017, the Affordable Care Act $(A C A)^{1}$ and a number of its key provisions were subjected to repeated "repeal" and "replace" efforts in the United States (US) Congress. In this article, we identify policy positions and discuss advocacy activities by key stakeholder groups whose interests were affected by major design features of the ACA. We focus on advocacy efforts associated with interest groups from three sectors-healthcare providers, insurance, and businesses, sectors which have been called the "axis of opposition" to healthcare reform in the past (Brown, 2011). Our analysis yields insights relevant to Congress's consideration of ACA repeal and replace efforts in 2017 and the use of policy reform designs that seek to foster resource and incentive-based policy feedback effects.

The ACA repeal and replacement debates in 2017 reflect a pattern of policymaking that has become more common in recent years. For decades, scholars

\footnotetext{
${ }^{1}$ The ACA is formally entitled the Patient Protection and Affordable Care Act (PPACA), which is actually comprised of two pieces of legislation enacted in the first half of 2010. Like many others, we use the "ACA" title in this article.
} 
have asserted that "policies create politics" (Lowi, 1972; Schattschneider, 1935), and these arguments have fallen on receptive ears as scholars have documented an increasingly crowded "policy space" in modern governance (Hogwood \& Peters, 1982). Scholars now widely recognize that policymaking often seeks to alter and/or undo policies that have already been enacted. While policy feedback studies have proliferated due to this recognition, they have often focused on broad discussions of policy feedback effects and studies of mass public reactions to policy reforms (Campbell, 2012). Resource and incentive effects, while widely recognized, appear under-studiedperhaps because material incentives that typically underlie them are widely recognized motivators of political advocacy. We seek to address this gap in the literature and offer insights on interest group dynamics associated with the ACA and the connections between policy design, resource and incentive effects, and policy advocacy.

\section{The ACA: An Overview of the Law and Its Consideration in Congress}

The 2017 attacks on the ACA reform, or "Obamacare", were not surprising. The ACA was partisan and controversial in 2010 when it was debated and passed, and it continued to be so after enactment. The law's opponents have challenged the ACA in the US courts and voted to pass bills in Republican controlled Congresses seeking to repeal the law after its enactment, despite certain veto by President Obama, who signed the ACA into law. With the election of President Trump in 2016 and a Republican controlled Congress which had campaigned on ACA repeal and replacement, efforts to roll back the law in 2017 surprised no one.

In 2009 and 2010, the Democratic Congress that enacted the ACA was eager to take advantage of its control of Congress and the White House to achieve a legislative goal that had evaded it in the past. One key element of the legislative strategy was to build support, or at least some level of tacit cooperation, from key groups that had stymied healthcare reform in the past (Brill, 2015; Jacobs \& Skocpol, 2010; Quadagno, 2011). These groups, which Lawrence Brown has referred to as the "axis of opposition", included healthcare providers, the insurance industry, and the business community (Brown, 2008, 2011), and the ACA was designed in ways that would yield resource flows to these groups as it also sought expanded access to health insurance, lower healthcare costs, and increased healthcare quality.

The healthcare access provisions of the ACA expanded health insurance availability in multiple ways. First, the law included regulatory requirements on health insurance companies. These included requirements that insurance companies cover dependent children on their parents' health insurance policies to age 26 , a prohibition against health insurance requirements that discriminate against individuals with pre-existing health conditions, and requirements that health insurance policies cover certain "essential" health benefits ${ }^{2}$. Second, the law expanded eligibility for Medicaid to include more low-income people-specifically, childless adults. However, the federal enforcement mechanism for expanding Medicaid (elimination of federal Medicaid reimbursements to states choosing not to participate) was ruled unconstitutional by the US Supreme Court in the National Federation of Independent Businesses (NFIB) vs. Sebelius (2012) case $^{3}$, which made the Medicaid expansion optional for states. However, by May 2017, 32 statesincluding Washington DC-had opted to participate in Medicaid expansion (Dhue \& Tausche, 2017; Russell Sage Foundation, 2017). Third, the law required Americans to purchase health insurance or face a tax penalty for failing to do so, and it enabled development of health insurance exchanges in each state where individuals could purchase insurance policies to comply with this mandate. Fourth, the law provided federal subsidies to lower- and middle-income people through insurance premium tax credits and cost sharing payments. And fifth, the law required employers with 50 or more full-time employees to offer health insurance coverage for their employees, and it also provided targeted subsidies to smaller employers to assist them in paying costs associated with coverage.

The ACA also included provisions to reduce healthcare costs and increase the quality of healthcare ${ }^{4}$, but these goals were probably less relevant to pacifying the "axis of opposition" than were the access related provisions. As a result of the access-expanding provisions discussed above, by September 2016, the proportion of the US population without health insurance had dropped by more than 20 million to 28.2 million (National Center for Health Statistics, 2017). This expanded healthcare access was enabled by a reform strategy focused on increasing the number of persons seeking services from healthcare providers, expanding the numbers of persons with health insurance, and further supporting employmentbased health insurance. All of these areas of focus reflected a strategy which sought to align the access related goals of the law with the economic interests of healthcare providers, the insurance industry, and businesses.

While the election of President Trump and a Republican Congress in 2016 made repeal and replacement efforts inevitable, the Congressional debate over these measures and the repeated failures associated with them were not widely predicted. As Senator John McCain articulated in his widely covered speech on the floor of the US Senate preceding his deciding vote against one of the repeal and replace bills, the Congressional debates and consideration of the repeal and replacement

\footnotetext{
${ }^{2}$ These benefits were established by regulation in 2014, and included wellness and preventive care, mental health services, dental care for children, and others.

${ }^{3}$ This case also upheld the constitutionality of the individual mandate to purchase health insurance as a legitimate exercise of Congress's powers under the US Constitution.

${ }^{4}$ For an overview of the ACA, see Kaiser Family Foundation, 2013.
} 
of Obamacare did not follow "regular order". It was a highly partisan process with few formal hearings and little opportunity for public and interest group input. As a result, to a significant degree, the debate that did occur took place in the media. In spite of these unusual circumstances (or, given Senator McCain's speech and decisive vote, perhaps in part because of them?), all four major ACA repeal bills considered were defeated in the Senate.

In spite of these defeats in Congress, ACA opponents did experience some public policy successes in weakening the law-particularly during the latter part of 2017. The Trump administration took administrative actions to weaken the law in the fall of 2017, including elimination of cost-sharing payments to insurance companies to offset the costs of medical treatments for high risk/cost persons. Congress also repealed tax penalties for individuals failing to comply with the "individual mandate" to purchase health insurance in a tax reform bill passed late in the year. These and other policy changes clearly undermined the reform, and created further uncertainties around individual healthcare insurance markets across the states. Viewed in totality, these actions also further undermined the stability of individual health insurance markets, which had already been compromised by reduced national efforts to publicize open enrollment periods for healthcare insurance exchanges, with the result that a number of health insurance companies sought to reduce their participation in the exchanges.

\section{Theoretical Foundations: Policy Feedback Effects and ACA Policy Advocacy}

Resources have long been recognized as a motivating factor for interest group engagement in pluralist theory and in American government (Dahl, 1971). Interest groups engage to protect their material interest. However, studies of the tie between interest group engagement and resources and related incentives have not often been a major point of focus in studies of policy feedback. Broadly speaking, policy feedback refers to "how policies, once passed, influence political dynamics going forward" (Lowi, 1972; Patashnik, 2008, p. 29; Schattschneider, 1935). While there are several approaches to the study of policy feedback (see Jacobs \& Weaver, 2015, for an overview), our work here is particularly informed by work in the historical institutionalist tradition (Patashnik, 2008; Pierson, 1993).

While scholars have argued that policy affects politics for quite some time (Lowi, 1972; Schattschneider, 1935), Pierson called attention to policy feedback effects and offered a framework for understanding differing forms they can take (Pierson, 1993). He argued that policy feedback may affect interest groups, state actors and capacities, and mass publics, and suggested that it can take different forms. One form of policy feedback relates to resource effects, which is the impact of public policies in conferring resources on particular groups or individuals. Incentive effects, by contrast, refer to the manner in which public policies "influence the probability of particular outcomes and the payoffs attached to those outcomes" (Pierson, 1993, p. 598). While these two kinds of policy feedback effects are analytically distinct, they may both contribute to the development of material stakes or investments on the parts of particular interest groups, which-in turn-may affect their constituency interests and the diversity and cohesiveness of their policy advocacy efforts (Patashnik, 2008, p. 31). Interpretive effects, by contrast, focus on public policies as sources of information and meaning, which can also affect subsequent political and policymaking processes by influencing how groups and individuals obtain and interpret information (Pierson, 1993, p. 611).

Policy feedback effects also differ regarding their likely impacts on subsequent policymaking. Scholars of policy feedback in the historical institutionalist tradition have suggested that policy may be self-reinforcing ("positive") or self-undermining ("negative"), depending on whether its effects tend to induce policy stability/expansion or policy rollback/re-orientation (Jacobs \& Weaver, 2015; Weaver, 2010). They have also emphasized the time-dependent characteristics of policy feedback and the post-enactment patterns of group support and/or opposition that may occur over time (Karch \& Rose, 2017; Pierson, 2000). Taken together, these and other considerations mean that existing policies may influence subsequent policymaking in ways that vary both over time and across policies.

Patashnik (2008) drew upon the conceptual foundations in Pierson's work and emphasized the importance of policy feedback in influencing the sustainability of public interest reforms. In this regard, he argued that two "over-arching feedback effects are crucial" (Patashnik, 2008, p. 31). These feedback effects relate to the effect of the reform on identities and cohesion of key stakeholders and to the impact of the reform on the investments of key actors. In the latter case, where interest group investments associated with the reform are substantial, policy advocates are expected to mobilize to protect those investments. By contrast, where investments are modest, political advocacy in support of the reform are expected to be minimal as well. In the former case, stable group identities and political affiliations may yield stable constituencies which advocate cohesively in defense of the reform. By contrast, more fluidity in stakeholder group coalitions may make interest group advocacy patterns more unpredictable.

An important point to recognize in this regard is that the ability of policies to enable major post-reform investments and stable coalitions of interest groups are not pre-determined. Rather, these kinds of policy feedback effects - and therefore the capacity of reforms to "remake politics" - is "contingent, conditional, and contested" (Patashhnik \& Zelizer, 2013). Relatedly, one would therefore expect that the existence of significant post-reform investments and more stabilized coalitions would increase the likelihood of stronger advocacy ef- 
forts in support of the reform, but would not determine it altogether. In short, the path from policy design features of a reform to stakeholder investments and strengthened and stabilized stakeholder coalitions supporting the reform to clear and effective advocacy efforts is probabilistic and path dependent rather than fully predetermined by the design of the reform.

Since the ACA's enactment, Patashnik and others have drawn on this body of policy feedback literature to analyze prospects for the law's sustainability. While this literature on the ACA is multifaceted, much of it has emphasized the complexity of the law's design and the potential confusion that this complexity yields for mass publics (Oberlander \& Weaver, 2015; Patashnik \& Zelizer, 2013). Other portions of it have focused on the importance of partisanship in affecting citizen perceptions of the ACA and its implementation (Chattopadhyay, 2018; Oberlander, 2016).

Missing from this literature is any systematic attempt to assess the extent to which groups that are economically affected by the law are taking clear positions in regard to it or taking active steps to protect their interests. Similarly missing is any attempt to understand whether or not key groups affected by the law are advocating for or against it in cohesive fashion, or are engaging it patterns of advocacy that are tied to specific threats to their resource-based interests. In this article, we begin an initial effort to fill these gaps in the literature on the ACA and its sustainability.

\section{Analytical Approach}

To assess likely resource-incentive policy feedback effects associated with the ACA's policy design and policy advocacy efforts of affected groups relating to repeal and replacement of the ACA in 2017, we draw on existing literature to discuss the likely resource-incentive effects of the ACA on groups within the healthcare, insurance, and business sectors. We also investigate patterns of ACA policy advocacy in 2017 for seven key groups in these sectors. Our investigations focus on two broad questions:

Question 1: Did key groups from the healthcare, insurance, and business sectors actively support the ACA and its key access related provisions against attempts to repeal/replace it in 2017 ?

Question 2: To what degree do patterns of interest group policy advocacy during the 2017 ACA repeal/replace debates in the US Congress reflect: a) advocacy consistent with resource-incentive policy feedback effects?; b) the development of cohesive coalitions supportive of the ACA?, and; c) chronological variations in advocacy efforts that appear tied to resource-incentive based interests?

\subsection{Descriptions of the Groups and Rationale}

Our analysis focuses on key groups which constitute significant portions of Brown's "axis of opposition" to past healthcare reform efforts and which were cultivated by policy design features of the ACA. We chose these groups from the healthcare, insurance, and business sectors, based on the likelihood they would be affected by the law and its implementation, as well as their key historical roles in healthcare reform policy debates (Brown, 2011).

The American Medical Association (AMA) is the largest single physician group in the US, with membership of approximately $20 \%$ of all practicing physicians. However, the association also represents many more physicians, estimated at around $90 \%$, through its House of Delegates (Graham, 2016). More than 190 medical society specialties and state level societies cast votes on policies in this forum (Graham, 2016). The AMA has also spent substantially more on lobbying than any other healthcare professional group (OpenSecrets, n.d.).

The American Hospital Association (AHA) is the national organization that represents hospitals and health care networks. Its membership is approximately 5,000 hospitals, health care systems, networks, and care providers, along with 43,000 individual members (AHA], 2018). The Federation of American Hospitals (FAH) is the national advocate for investor-owned or managed community hospitals and health systems in the US. Its membership includes over 1,100 health care facilities. Both groups were included in the analysis in order to ensure that both non-profit and for-profit health care facilities are represented.

America's Health Insurance Plans (AHIP) is the national association representing insurance providers. AHIP states that it "advocates for public policies that expand access to affordable health care coverage to all Americans through a competitive marketplace that fosters choice, quality, and innovation" (AHIP, 2018). Their membership includes life and health insurance companies, managed care organizations, Blue Cross and Blue Shield Plans, self-funded plans, cooperatives, fraternal societies, disease management organizations, HSA banks, and third party administrators (AHIP, 2018). AHIP represents more than 175 insurance organizations.

The US Chamber of Commerce is the world's largest business organization representing the interests of more than 3 million businesses of all sizes, sectors, and regions ranging from small local businesses to large industry leaders (US Chamber, n.d.). The National Federation of Independent Business (NFIB) is an organization that advocates for small business owners. It has approximately 325,000 members and locations in all 50 US states and Washington DC. Their policy areas of interest include healthcare, taxes, labor, and regulatory reform (NFIB, n.d.). The Small Business Majority provides education and resources to their network of around 55,000 small business owners and over 1,000 business groups in the United States. Their purpose is policy advocacy and entrepreneurship, focusing on issues related to capital, healthcare, taxes, retirement, paid leave and other policies directly impacting entrepreneurship (Small Business Majority, n.d.). The Chamber of Commerce and 
NFIB are among the top business organizations spending on lobbying activities (OpenSecrets, n.d.). The SBM is a liberal leaning organization that represents business interests that are not well represented by the other two groups included in the business sector portion of our sample. Small business owners, self-employed individuals, and small business employees are reported to make up more than half of enrollees in ACA marketplace plans (Chase \& Arensmeyer, 2018). Similarly, a 2017 US Treasury Department analysis shows that small business and self-employed sole proprietor tax filers were more likely to obtain health insurance coverage through an exchange plan than other employee types included in their analysis (US Department of Treasury, 2017). SBM's focus appears well aligned with these small business interests.

\subsection{Data Collection}

Because debates about the ACA have often focused on the law as a whole, we focused initial attention on policy feedback associated with the entire law. However, we are also concerned about the portions of the law that have resource implications for the groups we are investigating, so we also collected data on positions of key groups on its healthcare access related provisions.

Key access related provisions of the ACA relate to regulating health insurance, expanding individual healthcare insurance markets, and strengthening the employment-based portion of the healthcare insurance market. Specific insurance regulatory provisions included requirements that insurance policies cover dependents until age 26 , individuals with pre-existing conditions, and certain essential health benefits. The individual health insurance market-related provisions include Medicaid expansion, the individual mandate and associated health insurance exchanges, and individual insurance subsidies. The employment market-related provisions we investigated include the mandate that employers with 50 or more employees provide health insurance and the tax subsidies that accrue to employers to offset costs of healthcare provision.

To investigate advocacy-related activities of the above groups in 2017, we reviewed the websites of the selected groups, and supplemented that review with key word searches to identify documents and evidence generated by those groups but not found on the groups' websites $^{5}$. Our searches focused in two areas: 1) the taking of a public position in support or opposition of the ACA as a whole and of the key access related provisions mentioned above and 2) the nature and intensity of policy advocacy relating to the law, as indicated by the types of advocacy activities undertaken and the number of advocacy efforts identified by documents obtained through our searches. While we focused particularly on policy advocacy relevant to ACA repeal and replacement de- bates during 2017, our website and key word searches also yielded evidence regarding group positions and policy feedback efforts undertaken prior to that year. Earlier data that are not relevant to the 2017 repeal and replacement debates are not directly addressed in our findings, but do inform our discussions of ACA policy advocacy.

To ascertain the positions and advocacy activities of the organizations investigated, we collected: 1) position statements; 2) documents reflecting efforts to influence legislation such as letters to key policy decision-makers and Congressional testimony, and; 3) documents reflecting efforts targeted toward the broader public, such as public statements and press releases. We then coded the documents to reflect support or opposition for the ACA and its provisions, as well as the nature and extent of policy feedback effort undertaken by each of the groups mentioned above. Our coding also differentiated between policy advocacy efforts by individual groups in our sample and efforts in which groups in our sample joined together to advocate for their shared interests. We also coded data based on timing associated with key chronological stages in the 2017 ACA Congressional debates.

\subsection{Coding and Analysis}

Our website reviews and internet searches enabled identification of documents developed by the seven interest groups to advocate publicly regarding the ACA and/or its access related provisions in 2017 . We used these documents to code the groups' public support or opposition to the ACA as a whole in 2017 and-where possibleto key provisions as well. We applied a three-point coding scheme:

- O-Clear/documented opposition to the law/ provision;

- N-Neutral-no clear/documented position found/identified;

- S-Clear/documented support for the law/ provision.

The second portion of our analysis focused on ascertaining the extent and nature of policy advocacy based on the documents collected. Documents reflecting policy advocacy were coded to reflect the types of advocacy undertaken, including letters to decision-makers and testimony before Congress and press releases and public statements disseminated toward the broader public. We also analyzed chronological patterns of policy advocacy efforts to ascertain how they aligned with key stages of the repeal and replace debate in Congress during 2017. And finally, we also identified the extent to which the groups we investigated coalesced with one another to express their interests jointly, based on the documents collected.

\footnotetext{
${ }^{5}$ This keyword search data collection effort involved identifying the groups we are investigating and conducting keyword searches on the worldwide web based on their names, specific repeal/replacement efforts ("American Healthcare Act", for example), the ACA, and key ACA provisions being investigated. Documents resulting from those searches were then collected, organized, and stored electronically for use and reference.
} 


\section{Findings}

Our findings suggest that groups in all three key interest group sectors advocated for or against specific ACA provisions in ways that are consistent with their perceptions of their resource-incentive based interests, although these interests were not clear-cut in all cases and positions varied across groups. Table 1 summarizes findings on advocacy positions taken by groups in our sample, and Tables 2 and 3 summarize data collected on the extent of advocacy efforts identified and the timing of these efforts, respectively. Below, we review available information relevant to resource-incentive impacts of the ACA, and discuss findings presented in these tables, by sector.

\subsection{The Healthcare Sector: Hospitals and Healthcare Providers}

The ACA and its implementation has had significant impacts on American healthcare providers. Impacts on hospitals are relatively well-documented, as hospitals saw an increase in patient volume due to growth in the health insured population and hospital admissions are reported to have grown approximately 3-4\% a year prior to 2017 (Barkholz, 2017). Also, under US law, hospitals are required to provide care to the indigent, and the ACA's expansion of Medicaid is reported to have helped reduce burdens associated with this care-by $\$ 6.2$ billion in Medicaid expansion states alone (Dranove, Garthwaite, \& Ody, 2017). Indeed, the FAH and the AHA jointly commissioned a study of the impact of ACA repeal on hospitals, and it found that loss of insurance coverages associated with ACA repeal would lead to hospital revenue losses of \$165 billion or more (Dobson, DaVanzo, Haught, \& Luu, 2016).

The economic impacts of the ACA on (non-hospital) healthcare providers appear less well documented. Some have argued that healthcare providers have been negatively impacted by the law due to costs associated with increased healthcare regulation (Anderson, 2014), while others have argued that the healthcare industry has benefited from increased patient volume and employment associated with the expanded availability of health insurance (Page, 2013; Zhen, 2015). These competing conclusions suggest that the ACA's impacts are complex and may affect individual healthcare providers differently. Recent polls, however, suggest that only $15.1 \%$ of primary care physicians support full repeal of the law, while most (73\%) support changes to the law short of repeal (Pollack, Armstrong, \& Grande, 2017). While primary care physicians (PCPs) are only one specialty and are not representative of all physicians, "they are important for informing the public debate, given PCPs' central role in the health care system" (Pollack et al., 2017).

As the data presented in Table 1 indicate, the AHA, the $F A H$, and the AMA all took positions supportive of the ACA as a whole in 2017. They also took positions on specific provisions of the law that were consistent with their common economic interests. For example, during the course of the year, all three groups took positions supportive of ACA provisions on Medicaid expansion, the individual mandate to purchase health insurance, and cost-sharing payments which subsidized healthcare costs for specific individuals-all of which support their ongoing interests in a steady stream of paying insurance and healthcare service consumers. The AMA, AHA, and FAH also took positions supportive of access-related health insurance regulatory provisions, which effectively expand healthcare consumer markets, although their support of these provisions-with the exception of the pre-existing condition provision-appears less consistent than their support for the individual health insurance market provisions based on the documents we reviewed. Perhaps not surprisingly, we did not find strong statements of support (or opposition) from the groups in the healthcare provider sector regarding the employer mandate and small business subsidies.

The data presented in Table 2 suggest that groups in the healthcare provider sector were more actively engaged in defending the ACA than were the groups we investigated from other sectors. In the table, we report a total of 95 activities reflecting ACA policy advocacy efforts, and $58(61 \%)$ came from the three groups in this industry sector. The advocacy efforts undertaken also appear to reflect the relatively closed nature of the Congress's 2017 deliberations on the ACA. Twenty-three of the documents compiled reflect direct communications to lawmakers through letters and/or testimony. By contrast, of the advocacy documents identified, thirty-two were press releases and public statements of various kinds, suggesting that publicly oriented interest group advocacy efforts may have been a more prevalent advocacy approach than direct communications with legislators in Congress. It is worth noting that there were multiple cases where groups within the healthcare provider and insurance sectors joined together to oppose specific repeal and replacement efforts. These coalition efforts included activities to support continuation of cost reduction sharing payment subsidies to individuals, continuation of the individual mandate, and Medicaid expansion.

The data in Table 3 reveal that advocacy efforts by healthcare provider groups occurred throughout the 2017 year, but were most prevalent during the Spring and Summer months as repeal and replace bills were considered in the House and Senate. The first joint letters we were able to identify involving these groups, AHIP, and the US Chamber of Commerce were released in April 2017 and focused on support for continuation of cost sharing payments.

\subsection{The Health Insurance Industry}

Insurance companies are major stakeholders in health reform, as they are directly affected by both regulatory 
Table 1. Positions of key groups on the ACA and its healthcare access provisions, by sector for 2017.

\begin{tabular}{|c|c|c|c|c|c|c|c|c|c|c|}
\hline \multirow{2}{*}{\multicolumn{2}{|c|}{$\begin{array}{l}\text { Industry Sector/ } \\
\text { Major Groups }\end{array}$}} & \multirow{3}{*}{$\begin{array}{c}\text { ACA Law as } \\
\text { a Whole* }\end{array}$} & \multicolumn{6}{|c|}{ ACA-Major Healthcare Access Provisions* } & \multirow{2}{*}{\multicolumn{2}{|c|}{$\begin{array}{l}\text { Employment-Based Health } \\
\text { Insurance Market }\end{array}$}} \\
\hline & & & \multicolumn{3}{|c|}{ Health Insurance Provisions } & \multicolumn{3}{|c|}{ Individual Health Insurance Market } & & \\
\hline Sector & $\begin{array}{l}\text { Major } \\
\text { Groups }\end{array}$ & & $\begin{array}{c}\text { Young } \\
\text { Adults on } \\
\text { Parents' } \\
\text { Insurance }\end{array}$ & $\begin{array}{c}\text { Pre- } \\
\text { Existing } \\
\text { Conditions }\end{array}$ & $\begin{array}{c}\text { Essential } \\
\text { Health } \\
\text { Benefits }\end{array}$ & $\begin{array}{c}\text { Medicaid } \\
\text { Expansion }\end{array}$ & $\begin{array}{l}\text { Individual } \\
\text { Mandate } \\
\text { and Health } \\
\text { Insurance } \\
\text { Exchanges }\end{array}$ & $\begin{array}{l}\text { Individual } \\
\text { Subsidies }\end{array}$ & $\begin{array}{l}\text { Employer } \\
\text { Mandate }\end{array}$ & $\begin{array}{c}\text { Small } \\
\text { Business } \\
\text { Subsidies }\end{array}$ \\
\hline Healthcare & American & & & & & & & & & \\
\hline \multirow[t]{3}{*}{ Providers } & $\begin{array}{l}\text { Medical } \\
\text { Association }\end{array}$ & $\mathrm{s}$ & & $\mathrm{s}$ & $\mathrm{s}$ & $\mathrm{s}$ & $\mathrm{s}$ & $\mathrm{s}$ & & \\
\hline & $\begin{array}{l}\text { American } \\
\text { Hospital } \\
\text { Association }\end{array}$ & $\mathrm{s}$ & & $\mathrm{s}$ & $S$ & $\mathrm{~s}$ & $\mathrm{~S}$ & $\mathrm{~s}$ & & \\
\hline & $\begin{array}{l}\text { Federation } \\
\text { of American } \\
\text { Hospitals }\end{array}$ & $\mathrm{s}$ & & $\mathrm{s}$ & & $\mathrm{s}$ & $\mathrm{s}$ & $\mathrm{s}$ & & \\
\hline Insurance & AHIP & $\mathrm{s}$ & & $\mathrm{s}$ & & $\mathrm{s}$ & $\mathrm{s}$ & $S$ & & \\
\hline \multirow[t]{3}{*}{ Business } & NFIB & 0 & & & 0 & & 0 & & 0 & \\
\hline & US Chamber & 0 & & & & & & $\mathrm{~s}$ & 0 & \\
\hline & $\begin{array}{l}\text { Small } \\
\text { Business } \\
\text { Majority }\end{array}$ & $\mathrm{s}$ & & $\mathrm{S}$ & & $\mathrm{S}$ & & $\mathrm{s}$ & & \\
\hline
\end{tabular}


Table 2. Advocacy efforts: Congressional consideration of ACA repeal \& replace legislation.

\begin{tabular}{|c|c|c|c|c|c|c|c|}
\hline \multicolumn{2}{|c|}{ Sectors \& Groups } & \multicolumn{3}{|c|}{ Advocacy Documents/Efforts * } & \multicolumn{3}{|c|}{ Totals } \\
\hline Sectors & Groups & $\begin{array}{c}\text { Policy \& } \\
\text { Issue Briefs } \\
\text { (joint } \\
\text { document**) }\end{array}$ & $\begin{array}{c}\text { Letters to } \\
\text { Decision-makers \& } \\
\text { Testimony Before } \\
\text { Congress (joint } \\
\text { documents**) }\end{array}$ & $\begin{array}{c}\text { Press } \\
\text { Releases/Public } \\
\text { Statements } \\
\text { (joint } \\
\text { documents**) }\end{array}$ & $\begin{array}{l}\text { Total } \\
\text { Advocacy } \\
\text { Efforts }\end{array}$ & $\begin{array}{c}\text { Total Sector } \\
\text { Efforts/ } \\
\text { Documents }\end{array}$ & $\begin{array}{l}\text { Total Joint } \\
\text { Advocacy } \\
\text { Efforts** }\end{array}$ \\
\hline \multirow{3}{*}{$\begin{array}{l}\text { Healthcare } \\
\text { Providers }\end{array}$} & AMA & 1 & $7(2)$ & $13(3)$ & 21 & \multirow{3}{*}{58} & 5 \\
\hline & $\mathrm{AHA}$ & $1(1)^{* * *}$ & $10(4)$ & $14(2)$ & 25 & & 7 \\
\hline & FAH & $1(1)^{* * *}$ & $6(4)$ & $5(2)$ & 12 & & 7 \\
\hline Insurance & AHIP & 0 & $8(3)$ & $4(2)$ & 12 & 12 & 5 \\
\hline \multirow{3}{*}{ Business } & NFIB & 0 & 4 & 3 & 7 & \multirow{3}{*}{25} & 0 \\
\hline & $\begin{array}{l}\text { Chamber of } \\
\text { Commerce }\end{array}$ & $1 * * *$ & $4(2)$ & $2(1)$ & 7 & & 3 \\
\hline & $\begin{array}{l}\text { Small } \\
\text { Business } \\
\text { Majority }\end{array}$ & 0 & 0 & 11 & 11 & & 0 \\
\hline & Totals & 4 & 39 & 52 & \multicolumn{2}{|c|}{95} & \\
\hline
\end{tabular}

Definitions: Policy \& Issue Briefs-documents focusing primarily on providing information and analysis concerning one or more issues relating to ACA.

Letters \& Testimony Before Congress - Letters, testimony, and/or statements targeted toward key federal ACA decision-makers.

Press Releases/Public Statements-Press releases or statements targeted toward the broader public.

Notes: * The numbers in the cells of this table indicate documents identified, which-in turn-reflect "efforts" of each of the groups relevant to ACA repeal and replace consideration in 2017; ** "Joint" documents are ones signed and/or released by more than one of the seven groups in this table. They reflect collaborative efforts by these groups to provide information and/or advocate for shared interests and/or concerns. The "Total Joint Advocacy Efforts" column of the table identifies the number of "joint" documents involving each group, and it reflects the sum of joint advocacy documents/efforts of each type (ie. briefs, letters/testimony, \& Press Releases/public statements) shown in parentheses [“( )"] for each group; *** These policy briefs are dated in December 2016, but informed 2017 repeal and replace deliberations.

changes in the insurance industry and efforts to expand health insurance access. While recent studies point toward challenges in setting premiums based on new and changing insurance rules in expanding individual insurance markets and the importance of the re-insurance supports provided by the ACA (Hall \& McCue, 2016), broader analyses accounting for Medicaid and Medicare revenues reveal substantial gains in stock prices and point toward positive financial performances in the industry as a whole (Sommer, 2017). In this turbulent context, insurance companies have repeatedly argued for efforts to stabilize insurance markets, which allow them to gain experience necessary to set premiums at levels that cover their costs. In this context, the impacts of the ACA on the insurance industry appear variable to date (Hall \& McCue, 2016), but there is clear and common interest in market stability which enables insurance companies to be profitable over the long term.

In 2017, after releasing a statement to the House Ways and Means Committee which identified ways to enable broad participation in the individual health insurance market without an individual mandate (AHIP, 2017), AHIP-the primary national association representing in- surance companies in Washington DC-consistently opposed proposals to repeal and/or replace the ACA. As the findings in Table 1 suggest, it also provided consistent support for key provisions associated with expanding the individual health insurance market-Medicaid expansion, the individual mandate, and individual subsidies, including the cost share subsidies paid to insurance companies to offset the costs of insuring a client pool that now includes more high cost customers. AHIP does not appear to have vocally opposed the expanded insurance regulations ushered in by the law, even though these regulations required changes in their operations and payment of claims which insurance companies might not have paid previously. While this may seem surprising to some, this finding may reflect the recognition among insurers that these regulations are a part of the agreements struck with Congress to expand health insurance markets as a part of the ACA.

The data in Tables 2 and 3 reveal significant efforts by AHIP to influence Congress's ACA deliberations during 2017, and these efforts were most prevalent during Senate consideration of repeal and replace legislation. Table 2 shows that we identified 12 documents 
Table 3. Advocacy efforts: Timeline of advocacy efforts during congressional consideration of ACA repeal \& replace legislation in 2017.

\begin{tabular}{|c|c|c|c|c|c|c|c|}
\hline \multicolumn{2}{|c|}{ Sectors and Groups } & \multicolumn{4}{|c|}{ Group Documents/Efforts, Divided by Timing of Release* } & \multirow[b]{2}{*}{$\begin{array}{c}\text { Total } \\
\text { Advocacy } \\
\text { Efforts }\end{array}$} & \multirow[b]{2}{*}{$\begin{array}{c}\text { Total } \\
\text { Joint } \\
\text { Advocacy } \\
\text { Efforts }\end{array}$} \\
\hline Sectors & Groups & $\begin{array}{l}\text { Months Prior to } \\
\text { Introduction of } \\
\text { ACA Repeal } \\
\text { Legislation } \\
\text { 12/1/16-3/6/17 } \\
\text { (joint } \\
\text { documents**) }\end{array}$ & $\begin{array}{c}\text { House } \\
\text { Consideration } \\
\text { of the AHCA } \\
3 / 7-5 / 4 / 17 \\
\text { (joint } \\
\text { documents**) }\end{array}$ & $\begin{array}{c}\text { Consideration } \\
\text { of Bills in } \\
\text { Senate } \\
5 / 5-9 / 30 / 17 \\
\text { (joint } \\
\text { documents**) }\end{array}$ & $\begin{array}{c}\text { Tax Bill and ACA } \\
\text { Administrative } \\
\text { Changes } \\
\text { 10/1-12/31/17 } \\
\text { (joint } \\
\text { documents) }\end{array}$ & & \\
\hline \multirow{3}{*}{$\begin{array}{l}\text { Healthcare } \\
\text { Providers }\end{array}$} & AMA & 0 & $8(1)$ & $11(2)$ & $2(2)$ & 21 & 5 \\
\hline & $\mathrm{AHA}$ & $1(1)$ & $6(2)$ & $16(2)$ & $2(2)$ & 25 & 7 \\
\hline & $\mathrm{FAH}$ & $1(1)$ & $4(2)$ & $5(2)$ & $2(2)$ & 12 & 7 \\
\hline Insurance & AHIP & 1 & $2(1)$ & $7(2)$ & $2(2)$ & 12 & 5 \\
\hline \multirow{4}{*}{ Business } & NFIB & 1 & 3 & 3 & 0 & 7 & 0 \\
\hline & $\begin{array}{l}\text { Chamber of } \\
\text { Commerce }\end{array}$ & 1 & $4(1)$ & $1(1)$ & $1(1)$ & 7 & 3 \\
\hline & $\begin{array}{l}\text { Small } \\
\text { Business } \\
\text { Majority }\end{array}$ & 0 & 5 & 6 & 0 & 11 & 0 \\
\hline & Totals & 5 & 32 & 49 & 9 & 95 & \\
\hline
\end{tabular}

Notes: * The numbers in the cells of this table indicate documents identified, which-in turn-reflect "efforts" of each of the groups relevant to ACA repeal and replace consideration in 2017; ** "Joint" documents are ones signed and/or released by more than one of the seven groups in this table. They reflect collaborative efforts by these groups to provide information and/or advocate for shared interests and/or concerns. The "Total Joint Advocacy Efforts" column of the table identifies the total number of "joint" documents involving each group, and it reflects the sum of joint advocacy documents/efforts undertaken by each group during the time periods covered by the columns in the table, as shown in parentheses ["( )"] for each group.

reflecting AHIP policy advocacy efforts during 2017, and-in contrast to the efforts identified by healthcare providers - they were more frequently directed toward Congressional policymakers through letters or testimony. The table also reveals AHIP's involvement in at least five joint advocacy efforts, which included efforts to retain cost sharing reduction payments and the individual mandate to purchase health insurance. Table 3 reveals AHIP advocacy efforts occurring throughout the year, with particular prevalence in the summer months as the Senate debated the issue.

Overall, the positions taken by AHIP appear slightly more nuanced than the relatively straightforward supportive positions taken by the AHA and the AMA. During 2017, AHIP consistently advocated for ACA provisions supportive of an expanded individual insurance market, and particularly the Medicaid expansion and cost sharing payments they have received under the law. They appear to have been less vocal in providing feedback concerning the employment based market provisions, perhaps reflecting the fact that the ACA enabled more moderate changes in this market than in the individual market. And, not surprisingly, AHIP's policy advocacy also focused on maintaining stability for the insurance market as a whole.

\subsection{The Business Sector}

While observers agree that the ACA has affected American businesses economically, the nature and desirability of these effects have been the subject of debate. On one hand, the employer mandate and tax increases might be diverting funds from company growth. Employers and groups representing them have also complained about health insurance cost increases since enactment of the law (NFIB, 2016). On the other hand, others in the small business community have viewed the economic impacts of the law more favorably, and have argued that there have been reductions in the rate of health insurance premium growth (SBM, 2017). They also point out that expanded individual health insurance markets benefit small business owners and employees have greater access to health insurance, thus resulting in reduced "job lock" which may enable smaller businesses to be more competitive in attracting and retaining employees.

The data in Table 1 reveal that two of the three business groups we investigated-the more established NFIB and the US Chamber of Commerce-expressed clear opposition to the ACA as whole during the 2017 Congressional debates and particular opposition to the law's em- 
ployer mandate. The NFIB also took clear positions in opposition to other mandates in the law, including the individual mandate to buy health insurance and the required essential health benefits package ${ }^{6}$. We identified relatively fewer clear positions in opposition to other access related provisions of the ACA on the part of the Chamber of Commerce, but did find evidence of its support for continuation of cost sharing reduction payments. By contrast, the SBM was a vocal supporter of the ACA in the face of the multiple repeal and replace efforts considered during 2017. The SBM has also voiced clear support for key provisions of the ACA relating to pre-existing conditions, Medicaid expansion, and subsidies for individuals to purchase health insurance.

A review of the data on advocacy efforts by business groups in Tables 2 and 3 suggests that the extent of advocacy activity carried out by the business groups we investigated was lower than what was identified for the other sectors. Overall, we identified 25 documents reflecting advocacy activities across all three business groups in our sample. A disproportionate share of these documents $(11 / 25$, or $44 \%)$ came from the SBM, which-in contrast to the other two groups-opposed repeal and replacement of the ACA. The kinds of policy advocacy activities conducted by the three business groups we investigated also varied. We identified a total of fourteen documents reflecting policy advocacy efforts on the part of the NFIB and the US Chamber of Commerce combined, and these documents were split between efforts directed toward Congressional decision-makers and the general public. By contrast, we identified eleven documents reflecting policy advocacy efforts on the part of the SBM, and these documents predominantly reflected efforts to support public understandings of the ACA's impacts that are supportive of the law's continuation. It is noteworthy that we also found that the Chamber of Commerce joined with health provider and insurance groups in activities to support the continuation of cost sharing reduction payments to subsidize higher cost patients on the individual market. And, as was the case for the other interest group sectors we investigated, the data in Table 3 reveal heightened interest group advocacy during the Spring and Summer when Congress was debating ACA repeal and replacement legislation.

Overall, the findings discussed above suggest that advocacy efforts of the two major business groups are not much different than what might have been expected of them prior to the ACA reform. In this sense, they appear to remain a part of an "opposition" to the ACA health reform. It is also worth noting, however, that-at least as measured by the extent of evidence on their advocacy that is publicly available-the major two ACA opponent groups, the NFIB and the Chamber of Commerce, appear to have been less active in opposing the law than the other groups were in supporting it. By contrast, the SBM actively supported the ACA as expected, and it appears to have been more active in supporting the law than the NFIB and the Chamber of Commerce were in opposing it.

\section{Discussion and Implications}

The analyses above are best viewed as exploratory, but they do suggest that interest group dynamics associated with healthcare reform in the US have changed since Brown (2008) articulated the obstructionist roles performed by the "axis of opposition" about a decade ago. In 2017, key healthcare provider groups and the insurance industry appeared more supportive of health "reform" and healthcare access than they had been in the past. They engaged actively to defend the law's health insurance access provisions on multiple occasions during the year. However, the positions of major business groups that have long opposed American healthcare reform efforts-the NFIB and the Chamber of Commerce, in particular-remained similar to what they have been in the past, even though the Chamber of Commerce did actively support efforts by health provider groups and the insurance industry to continue cost sharing reduction payments which supported stability in the health insurance exchange markets. Our measures of the extent of group advocacy during 2017 also suggest that advocacy efforts supporting repeal and replacement of the law may have been less vociferous than the efforts made by groups which opposed the law's repeal and/or replacement.

These findings are consistent with what one might expect if the access expansion provisions of the ACA actually had the kinds of resource-incentive policy feedback effects that the law's crafters had hoped would materialize. Healthcare providers and the insurance industry benefited from expanded customer bases in the individual market and from resource subsidies and incentives that are tied to expanded access to healthcare. They took positions in support of the law and actively supported provisions that benefited them, including the cost sharing reduction payments and the individual mandate to purchase insurance. Their engagements in defending the ACA are also apparent in their decision to combine efforts with one another and go public with expanded efforts to support continuation of cost sharing payments and to oppose repeal of the individual mandate. Indeed, the data we present above suggests that these groups mobilized more actively to oppose repeal and replace efforts than the business groups did to support them. All of these findings, while preliminary, suggest that the strategy of tying expanded access to healthcare in ways that are consistent with the resource-incentive interests of health providers and the insurance industry was at least partially successful in building support for the ACA law.

However, the variations in policy advocacy patterns presented in our analyses also suggest that resourceincentive effects are subject to limitations affecting their

\footnotetext{
${ }^{6}$ In addition, it is worth noting that NFIB was the plaintiff in the 2012 Supreme Court case that allowed states to decline participation in Medicaid expansion, a point that is not reflected in Table 1's presentation of findings regarding policy advocacy efforts undertaken in 2017.
} 
impacts on political advocacy. Some of these limitations on the impact of resource-incentive effects are already recognized in the policy feedback literature. First, resource effects of existing policies may not always be clear, and they may also be experienced and perceived differently by different groups. Our analysis suggests multiple possible effects of the ACA on the insurance industry, some of which negatively impact industry resources (regulations requiring coverage of essential health benefits, for example) and others which tend to enhance industry resources (cost sharing subsidies, for example). How these effects "net out" for the industry as a whole and various members of it is not always clear. And, even if there is clarity on net effects and their distribution across groups, different groups may perceive these effects differently. For example, the NFIB is particularly concerned about regulations and costs to its members, while the SBM perceives a need for small businesses and their employees to have better access to health insurance. Thus, even clarity on resource-incentive effects may not necessarily yield clarity regarding how these effects are valued by differing groups, and these valuations may affect the extent and nature of political support provided by affected groups.

Second, resource-incentive effects do not fully explain policy advocacy patterns across ACA provisions. For example, while small businesses might be expected to oppose a mandate on employers to provide health insurance, we find no evidence that the SBM opposed this mandate. It thus appears that the positions of the organizations on individual ACA provisions may be driven by other factors-including ideological orientations of the groups themselves and strategic political considerations tied to the overall mix of provisions in the law and existing balances of political power-rather than by the resource-incentive effects of particular provisions. Groups with particular ideologies and/or strong ties to the political party in power, for example, may accept certain policy provisions that are not in their interest in order to maintain good relations with party leaders who can aid them in other ways.

And finally, our investigations reveal not only uncertainties and differing perceptions on resource-incentive effects and potential strategic considerations relevant to policy advocacy on individual provisions, but also changes over time. This limitation associated with the impact of policy feedback effects is well recognized in the policy feedback literature (Karch \& Rose, 2017; Patashnik \& Zelizer, 2013), and it-along with the factors abovesuggests that one cannot predict interest group policy advocacy on the basis of resource-incentive effects alone. During the course of 2017, for example, the data presented above shows significant variations in the extent of advocacy during the course of the year, with the most extensive interest group engagement occurring during the spring and summer months while repeal and reform legislation was being considered. This is not surprising, but does suggest that groups respond not only to re- sources and incentives, but also to the extent of perceived threat and opportunity in their environments at particular points in time.

While our investigations focused primarily on the 2017 repeal and replace debates in Congress, our key word searches yielded information not only on group positions taken in 2017, but also on positions and feedback provided between 2010 after the law's initial passage and the end of 2016. We uncovered evidence that several groups-the AMA, AHIP, and the Chamber of Commerce-became more supportive and/or less opposed to the ACA over time. For example, there was early debate among AMA members on whether or not to support the ACA (Meyer, 2010) and this debate was eventually resolved in ways that led the AMA to support the law consistently in 2017. A similar strengthening of support for the ACA's individual mandate is apparent in the trajectory of AHIP's communications to Congress on the individual mandate in 2017. Its early feedback to Congress on the individual mandate, for example, appeared to view the mandate's repeal as inevitable, while later feedback focused directly on preventing its repeal. Within the business sector, by contrast, the Chamber of Commerce appears to have vigorously opposed the law through 2014, the year many of its key provisions took effect. After that, the Chamber's President suggested that the ACA was here to stay (Whitney, 2014). In this context, it is perhaps not surprising that the Chamber's policy advocacy in opposition to the law in 2017 appeared less vocal than that of the NFIB, which appeared to oppose the law more vigorously and consistently. Consistent with Patashnik's (2008) analysis, the Chamber may have reached the point where it simply accepted the ACA and/or its overall structure as a new reality with which it must deal.

All of the factors discussed above-uncertainty and differing perceptions regarding resource-incentive effects, ideological orientations of affected groups, potential strategic complexities relating to the overall mix of provisions and the larger political context, and strategic adjustments in positions over time-appear to hold potential to influence the extent to which resourceincentive effects mobilize political action in any particular case. This suggests that efforts to understand patterns of interest group advocacy associated with policy reforms should account for not only resource-incentive effects, but also other variables such as those outlined above and perhaps others as well-including the extent to which key political institutions (such as Congress) signal openness to learning of and responding to interest group advocacy concerns.

It is important to recognize, however, that our findings are subject to a number of limitations. First, our analysis relates to just one policy reform in the US and Congress's reconsideration of it in one year (2017), so it is important to recognize that policy feedback dynamics may be different in other cases, circumstances, and/or national settings. In addition, within the context of the 
ACA, our assessment is based on investigations of just seven interest groups (albeit major and important ones), and our findings might be supplemented productively if other groups-or more specific subsets of them-were also investigated. Third, our selection of provisions to investigate was based on the likely interests of these seven groups in the ACA's access related provisions. The dynamics of resource-incentive based policy feedback at the level of legal provisions might be different if cost or quality related provisions received more focus in our analyses. Fourth, our data gathering processes were based on existing information on group websites and additional internet searches, so it is possible that we missed policy advocacy positions and/or activities that would provide a more comprehensive picture of likely impacts of ACA policy feedback effects. Fifth, while our analyses provide insight into patterns of ACA advocacy efforts, they are not designed to yield strong insights on the effects of these advocacy efforts on the final resolution of Congress's ACA repeal and replace debates. Finally, our analysis does not directly control for alternative factors which might explain the patterns of positions taken and advocacy efforts advanced during ACA the repeal and replace debates. We do not, for example, attempt to disentangle resourceincentive effects from ideological or partisan ties that might also help explain positions and advocacy efforts that were undertaken during 2017.

Nevertheless, our findings have implications for the design of policy reforms and future research. They suggest that policy reformers may productively draw on insights from resource-incentive theories as they seek to design sustainable reforms. However, they also point out that the utility of these insights may be limited in key respects. They may be limited by the extent to which the policies have uncertain resource-incentive effects, are subject to variable perceptions among key groups based on their ideological orientations and the values they associate with various policy feedback effects, and are subject to complex interconnections among reform provisions and factors in the larger socioeconomic-political context that affect strategic judgments made by affected groups.

Our findings also yield insights relevant to future research. First, future research on policy feedback effects should take account of resource-incentive effects, as well as other factors that may limit their impact and importance in particular circumstances. Second, the findings above suggest that policy feedback may give rise to advocacy dynamics that vary across provisions in a law, and which therefore hold the potential to unravel a reform through "a thousand cuts", rather than through full repudiation or repeal-an insight also noted by Patashnik (2008, p. 32). Future research on the contexts in which full repeal is likely to occur versus contexts where laws may unravel as a result of progressive adjustments to key provisions may therefore be appropriate, perhaps drawing on Patashnik's (2008) work in this area. Finally, our discussion highlights once again the importance of exist- ing literature suggesting that patterns of policy feedback and group advocacy may change over time (Patashnik \& Zelizer, 2013; Pierson, 2000; Karch \& Rose, 2017). This suggests that there may be value in studies focused on identifying factors that influence interest group decisions to change positions and/or alter policy advocacy efforts, and the likely magnitude and timing of these changes.

\section{Conclusion}

Patashnik and colleagues argue that the sustainability of public interest reforms turns on their capacities to remake politics (Patashnik, 2008), and they also suggest that there are limits to the impact of policy feedback effects because "the capacity of public policies to remake politics is contingent, conditional, and contested" (Patashnik \& Zelizer, 2013, p. 1072). Our findings reveal the existence of interest-group based policy advocacy patterns that appear consistent with resource-incentive effects of the ACA, and this suggests that there has been at least some "re-making" of politics associated with the ACA reform. The AMA, AHIP, key hospital groups, and even portions of the business community are now defending a major American healthcare reform (and/or portions thereof), rather than serving as an "axis of opposition" to expanded healthcare access. Although our analysis above does not directly address this point, this kind of political change may provide at least part of the explanation for why key portions of the ACA remained intact a year after the election of a unified Republican government that had campaigned on a platform advocating repeal and replacement of the ACA.

Our findings also suggest that the influence of resource-incentive effects on patterns of interest group advocacy may not be as straightforward as some might expect. Groups that perceive or value resource effects differently may engage in differing patterns of policy advocacy. Policy advocacy patterns also appear to differ across provisions in ways that run counter to what would be predicted by narrow applications of resourceincentive theories to specific provisions. These differences may be contingent on interconnections among ACA provisions and perhaps perceptions by interest groups that are conditioned by both their ideological orientations and broader political circumstances. Consistent with existing literature, our investigations also uncovered chronological variations in the positions and advocacy efforts undertaken by key groups, and this suggests that the timing of key challenges and opportunities may also affect policy advocacy patterns associated with resource-incentive effects.

Thus, while our findings are consistent with the idea that resource-incentive effects of public policies influence patterns of policy advocacy, they also suggest that the impacts of resource-incentive based policy feedback effects on interest group advocacy are not as simple as some might assume. Our hope is that this conclusion and the ideas on resource-incentive based policy advocacy 
expressed above may inform future research efforts to improve our understanding of both the current healthcare policy debate in the US and larger questions about policy feedback effects and reform.

\section{Acknowledgments}

We would like to thank the anonymous reviewers engaged by Politics and Governance and the journal's editors for their thorough and thoughtful reviews on an earlier draft of this paper. We made multiple changes in the manuscript in response to their valuable comments.

\section{Conflict of Interests}

The authors declare no conflict of interests.

\section{References}

America's Health Insurance Plans. (2017). Statement on "The individual mandate under the Affordable Care Act" submitted to the House Ways and Means Committee Subcommittee on Oversight. America's Health Insurance Plans. Retrieved from https:// www.ahip.org/wp-content/uploads/2017/02/state ment-for-WM-hearing-on-individual-mandate-01-24 -17.pdf

America's Health Insurance Plans. (n.d.). Advocating for the health insurance community and the consumers they serve. America's Health Insurance Plans. Retrieved from https://www.ahip.org/about-us/whatwe-do/who-we-are

American Hospital Association. (n.d.). The American Hospital Association. Retrieved from: https://www. aha.org/front

Anderson, A. (2014). The impact of the Affordable Care Act on the healthcare workforce. The Heritage Foundation. Retrieved from https://www. heritage.org/health-care-reform/report/the-impactthe-affordable-care-act-the-health-care-workforce

Barkholz, D. (2017). Hospital volumes laid low by high-deductible health plans. Modern Healthcare. Retrieved from http://www.modernhealthcare.com/ article/20170810/NEWS/170819994

Brill, S. (2015). America's bitter pill. New York, NY: Random House.

Brown, L. D. (2008). The amazing noncollapsing U.S. health care system: Is reform finally at hand. New England Journal of Medicine, 358, 325-327.

Brown, L. D. (2011). The elements of surprise: How health reform happened. Journal of Health Politics, Policy and Law, 36(3), 419-427.

Campbell, A. L. (2012). Policy makes mass politics. Annual Review of Political Science, 15, 333-351.

Chase, D., \& Arensmeyer, J. (2018). The Affordable Care Act's Impact on small business. The Commonwealth Fund. Retrieved from https://www.common wealthfund.org
Chattopadhyay, J. (2018). Is the Affordable Care Act cultivating a cross-class constituency? Income, partisanship, and a proposal for tracing the contingent nature of positive policy feedback effects. Journal of Health Politics, Policy and Law, 43(1), 19-67.

Dahl, R. (1971). Polyarchy: Participation and opposition. New Haven, CT: Yale University Press.

Dhue, S., \& Tausche, K. (2017, June 2). Republicans grapple with Medicaid as lawmakers return to Washington. CNBC. Retrieved from https://www.cnbc.com/ 2017/06/02/republicans-grapple-with-medicaid-ex pansion-as-they-return-to-dc.html

Dranove, D., Garthwaite, C., \& Ody, C. (2017). The impact of the ACA's Medicaid expansion on hospitals' uncompensated care burden and the potential effects of repeal. The Commonwealth Fund. Retrieved from http://www.commonwealthfund.org/publications/ issue-briefs/2017/may/aca-medicaid-expansion-hos pital-uncompensated-care

Dobson, A., DaVanzo, J., Haught, R., \& Luu, P. H. (2016). Estimating the impact of repealing the Affordable Care Act on hospitals. The American Heart Association. Retrieved from http://www.aha.org/content/ 16/impact-repeal-aca-report.pdf

Graham, J. (2016, December 22). Like a slap in the face: Dissent roils the AMA, the nation's largest doctor's group. StatNews. Retrieved from https:// www.statnews.com/2016/12/22/american-medicalassociation-divisions

Hall, M. A., \& McCue, M. J. (2016). How has the Affordable Care Act affected health insurers' financial performance. The Commonwealth Fund. Retrieved from http://www.commonwealthfund.org/publications/ issue-briefs/2016/jul/the-affordable-care-act-andhealth-insurers-financial-performance

Hogwood, B. W., \& Peters, B. G. (1982). The dynamics of policy change: Policy succession. Policy Sciences, 14(3), 225-245.

Jacobs, L., \& Skocpol, T. (2010). Healthcare reform and American politics. New York, NY: Oxford University Press.

Jacobs, A. M., \& Weaver, R. K. (2015). When policies undo themselves: Self-undermining feedback as a source of policy change. Governance: An International Journal of Policy, Administration, and Institutions, 28(4), 441-457.

Kaiser Family Foundation. (2013). Summary of the Affordable Care Act. Kaiser Family Foundation. Retrieved from https://www.kff.org/health-reform/fact-sheet/ summary-of-the-affordable-care-act

Karch, A., \& Rose, S. (2017). States as stakeholders: Federalism, policy feedback, and government elites. Studies in American Political Development, 31(1), 47-67.

Lowi, T. J. (1972). Four systems of policy, politics, and choice. Public Administration Review, 32(4), 298-310.

Meyer, H. (2010, November 30). AMA conservatives revolt against the individual mandate. Health $A f-$ fairs Blog. Retrieved from https://www.healthaffairs. 
org/do/10.1377/hblog20101130.008103/full

National Center for Health Statistics. (2017). Health insurance coverage: Early release of estimates from the national health interview survey, JanuarySeptember 2016. Centers for Disease Control and Prevention. Retrieved from https://www.cdc.gov/ nchs/data/nhis/earlyrelease/insur201702.pdf

National Federation of Independent Business v. Sebelius 2012567 U.S. 519 (USA).

National Federation of Independent Business. (n.d.). The National Federation of Independent Business. Retrieved from: https://www.nfib.com

National Federation of Independent Business. (2016). The unforeseen consequences of Obamacare. $\mathrm{Na}$ tional Federation of Independent Business. Retrieved from https://www.nfib.com/content/analysis/health care/the-unforeseen-consequences-of-obamacare72688

Oberlander, J. (2016). Implementing the Affordable Care Act: The promise and limits of health care reform. Journal of Health Politics, Policy, and Law, 41(4), 803-826.

Oberlander, J., \& Weaver, R. K. (2015). Unraveling from within? The affordable care act and self-undermining policy feedbacks. The Forum, 13(1), 37-62.

OpenSecrets. (n.d.) Opensecrets: Center for responsive politics. OpenSecrets. Retrieved from: https://www. opensecrets.org

Page, L. (2013). 8 ways that the ACA is affecting doctors' incomes. The NEJM Career Center. Retrieved from http://www.nejmcareercenter.org/minisites/rpt/8ways-that-the-aca-is-affecting-doctors-incomes

Patashnik, E. (2008). Reforms at risk what happens after major policy changes are enacted. Princeton, NJ: Princeton University Press.

Patashnik, E., \& Zelizer, J. E. (2013). The struggle to remake politics: Liberal reform and the limits of policy feedback in the contemporary American state. Perspectives on Politics, 11(4), 1071-1087.

Pierson, P. (1993). When effect becomes cause: Policy feedback and political change. World Politics, 45(4), 595-628.

Pierson, P. (2000). Increasing returns, path dependence, and the study of politics. American Political Science Review, 94(2), 251-267.

Pollack, C. E., Armstrong, K., \& Grande, D. (2017). A View from the front line-Physicians' perspectives on ACA repeal. New England Journal of Medicine, 376(6).
DOI: $10.1056 /$ NEJMp1700144.

Quadagno, J. (2011). Interest-group influence on the patient protection and affordability act of 2010: Winners and losers in the health care reform debate. Journal of Health Politics, Policy and Law, 36(3), 449-453.

Russell Sage Foundation. (2017). Medicaid expansion under the Affordable Care Act. Russell Sage Foundation. Retrieved from https://www.russellsage.org/ medicaid-expansion-under-affordable-care-act

Schattschneider, E. E. (1935). Politics, pressure, and the tariff. New York, NY: Prentice Hall.

Small Business Majority. (2017). The Affordable Care Act's impact on small business. Small Business Majority. Retrieved from https://www.smallbusiness majority.org/sites/default/files/resources/013017ACA-impact-small-biz-facts-figures-national.pdf

Small Business Majority. (n.d.). Small Business Majority. Retrieved from: http://www.smallbusinessmajority. org/

Sommer, J. (2017, March 18). Gripes about Obamacare aside, health insurers are in a profit spiral. New York Times. Retrieved from https://www.nytimes.com/ 2017/03/18/business/health-insurers-profit.html

United States Department of the Treasury. (2018). The rise of alternative work arrangements: Evidence and implications for tax filing and benefit coverage (Working Paper 114). Washington, DC: United States Department of the Treasury. Retrieved from https://www.treasury.gov/resource-center/taxpolicy/tax-analysis/Documents/WP-114.pdf

United States Chamber of Commerce. (n.d.). U.S. Chamber of Commerce: Standing up for American enterprise. United States Chamber of Commerce. Retrieved from https://www.uschamber.com

Weaver, R. K. (2010). Paths and forks or chutes and ladders? Negative feedbacks and policy regime change. Journal of Public Policy, 30(2), 137-162.

Whitney, E. (2014, January 31). Joining GOP trend, US Chamber of Commerce urges fix, not repeal, of Obamacare. Kaiser Health News. Retrieved from https:// khn.org/news/us-chamber-of-commerce-urges-fixing -obamacare

Zhen, E. (2015, October 1). The health economics of the Affordable Care Act. The Penn Wharton Public Policy Initiative. Retrieved from https:// publicpolicy.wharton.upenn.edu/live/news/861-thehealth-economics-of-the-affordable-care-act

\section{About the Authors}

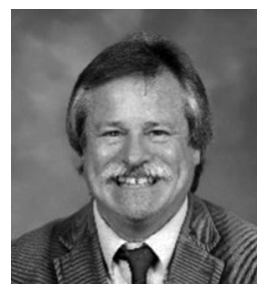

John Hoornbeek (PhD, MPA) is an Associate Professor in the College of Public Health at Kent State University, where he also serves as Director of the Center for Public Policy and Health. His research and teaching interests lie in environmental and health policy, policymaking, intergovernmental relations, and public management. He earned his Doctoral Degree from the University of Pittsburgh, his Master's Degree from the University of Wisconsin-Madison, and his Bachelor's Degree from Beloit College. 


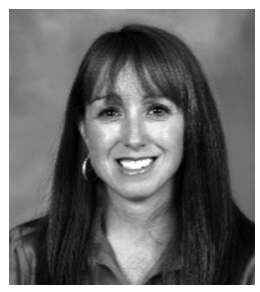

Bethany Lanese (PhD) is an Assistant Professor of Health Policy and Management at Kent State University. Her areas of interest include health reform and policy, health disparities, and mental health. She has worked in Healthcare Management at a nonprofit community hospital and held an academic appointment at Eastern Michigan University. She earned her Doctoral Degree at Wayne State University, her Master's Degree from the University of Maryland European Systems, and her Bachelor's Degree from the University of Colorado, Colorado Springs.

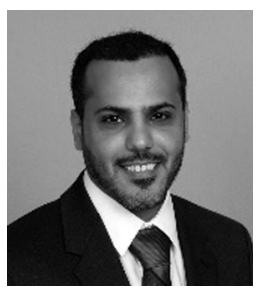

Mutlaq Albugmi (MPH) is a PhD student in the College of Public Health at Kent State University (KSU), where he also works as a Graduate Research Assistant for the Center for Public Policy and Health. His areas of research and teaching interest are in health policy, health system reform, and health quality. Mr. Albugmi earned his Master's degree from KSU, after working in the healthcare industry in Saudi Arabia prior to moving to the United States.

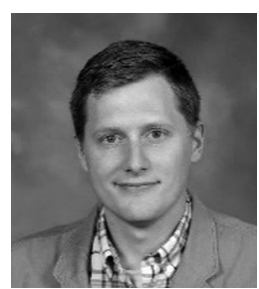

Joshua Filla (MPA) received his Master's of Public Administration from Kent State University's Political Science Department and earned his undergraduate degree from KSU's School of Journalism and Mass Communication. He works with the Center's staff, affiliates, and partners on projects in a variety of subject areas, including intergovernmental collaboration and environmental policy. 